\title{
AKTIVITAS ANTIBAKTERI EKSTRAK DAUN JERUK SAMBAL (CITRUS MICROCARPA) TERHADAP BEBERAPA BAKTERI PATOGEN
}

\author{
Maya Apriliani*, Adam M.Ramadhan, Laode Rijai \\ Laboratorium penelitian dan pengembangan FARMAKA TROPIS \\ Fakultas Farmasi Universitas Mulawarman, Samarinda, Kalimantan Timur \\ *Email: mayaapriliani11@gmail.com
}

\begin{abstract}
ABSTRAK
Daun jeruk sambal (Citus Microcarpa) merupakan jenis tanaman yang telah tersebar diseluruh indonesia. Daun jeruk sambal merupakan jenis buah-buahan yang memiliki rasa yang cukup asam dan daunnya memiliki aroma yang khas. Penelitian ini bertujuan untuk mengetahui aktivitas antibakteri dari daun jeruk sambal terhadap beberapa bakteri uji serta mengetahui konsentrasi terbaik sebagai antibakteri. Sampel dikumpulkan kemudian dilakukan maserasi dengan pelarut etanol 96\%. Bakteri yang diuji ialah Staphylococcus aureus, Salmonella thypi, Bacillus subtilis dan Escherichia coli. Pengujian antibakteri dengan metode difusi agar menggunakan medium natrium agar konsentrasi 10\%, 20\%, 30\%, 40\% dan $50 \%$. Hasil yang didapat dengan mengukur zona bunuh dari setiap konsentrasi dengan paper disc. Diameter zona bunuh bakteri Escherichia coli $(8,11 \mathrm{~mm})$, Bacillus subtilis sebesar $(7,57 \mathrm{~mm})$, Staphylococcus aureus $(7,19 \mathrm{~mm})$ dan Salmonella typhi $(7,59 \mathrm{~mm})$. Konsentrasi terbaik sebagai antibakteri ekstrak etanol 96\% daun jeruk sambal dalam membunuh bakteri Staphylococcus aureus, Salmonella thypi, Bacillus subtilis dan Escherichia coli yaitu pada konsentrasi 50\%.
\end{abstract}

Kata Kunci : Antibakteri, Citrus Microcarpa, Paper Disc

\section{PENDAHULUAN}

Indonesia sejak dulu telah ada pengobatan secara sederhana atau tradisional menggunakan bahan alam sebagai media pengobatan. Bahan alam sebagai media pengobatan tradisional digunakan oleh masyarakat Indonesia untuk menanggulangi berbagai masalah kesehatan. Hal ini disebabkan karena keanekaragaman flora yang berkhasiat sebagai bahan obat dan biasanya digunakan berdasarkan kepercayaan empiris yang bersifat turun temurun maupun yang ditemukan oleh para ilmuwan. Salah satu penyakit yang dialami adalah infeksi. Infeksi merupakan salah satu penyakit yang disebabkan oleh bakteri. Adapun 
bakteri yang dapat menyebabkan infeksi yaitu Staphylococcus aureus, Salmonella thypi, Bacillus subtilis dan Escherichia coli. Antibiotik merupakan obat sintetik yang digunakan sebagai menghambat ataupun membunuh perkembang bakteri yang menyebabkan infeksi. Semakin parahnya infeksi maka semakin besar juga untuk menggunakan antibiotik, hal ini dapat menyebabkan terjadinya resisten tubuh terhadap antibiotik. Sehingga dari hal tersebut dapat menggunakan bahan alam sebagai pengganti obat untuk dapat meredakan dan menghilangkan infeksi disertai radang yang disebabkan oleh bakteri.

Daun jeruk sambal (Citrus Microcarpa) merupakan salah satu tanaman yang terdapat di indonesia dikenal secara luas di Kalimantan Barat. Buah jeruk ini biasa dikonsumsi dalam bentuk jus dan digunakan sebagai bumbu masak, sedangkan kulitnya digunakan sebagai pelengkap masakan tertentu. (Wulan, 2013) uji fitokimia dan uji aktivitas antioksidan untuk mengetahui potensi kulit buah jeruk sambal sebagai sumber senyawa antioksidan.

Penelitian ini bertujuan untuk mengidentifikasi senyawa metabolit sekunder serta mengetahui aktivitas antibakteri ekstrak daun jeruk sambal (Citrus Microcarpa) dengan bakteri uji Staphylococcus aureus, Salmonella thypi, Bacillus subtilis dan Escherichia coli.

\section{METODE PENELITIAN}

\section{Bahan}

Bahan yang digunakan ialah daun jeruk sambal (Citrus Microcarpa) yang diperoleh pada pekarangan rumah masyarakat. Pelarut yang digunakan berupa etanol 96\% dengan menggunakan tahapan maserasi. Bakteri yang digunakan sebagai uji ialah Staphylococcus aureus, Salmonella thypi, Bacillus subtilis dan Escherichia coli. Medium yang digunakan ialah Natrium Agar (NA), $\mathrm{NaCl}$ 0,9\% sebagai media pensuspensi bakteri, Aquadest digunakan sebagai media melarutkan ekstrak yang akan diujikan, paper disc atau kertas saring digunakan sebagai media penyerat ekstrak uji antibakteri. 


\section{Peralatan}

Peralatan yang digunakan dalam uji antibakteri ialah autoklaf, batang pengaduk, cawan, erlenmeyer, hot plate, rotary evaporator, inkubator, LAF (Laminal Air Flow), waterbath, porselin, rak tabung, tabung reaksi, timbangan analitik, spoid dan lainnya.

\section{Prosedur Penelitian}

\section{Pengambilan sampel}

Daun jeruk sambal (Citrus Microcarpa) sebagai sampel uji diambil secara utuh kemudian dilakukan pencucian untuk menghilangkan kotoran pada daun, setelah dicuci dilakukan pemotongan sampel segar atau dilakukan proses perajangan sampel. Setelah itu sampel ditimbang dan dikeringkan dengan oven pada suhu $40^{\circ} \mathrm{C}$. Kemudian ditimbang berat simplisia setelah dilakukan pengeringan dengan oven tersebut.

\section{Ekstraksi}

Simplisia daun jeruk sambal yang telah kering diekstraksi menggunakan pelarut etanol 96\% dengan metode maserasi selama 3×24 jam. Ekstrak etanol 96\% hasil rendaman simplisia dilakukan penyaringan dan dilakukan proses pemekatan ekstrak dengan menggunakan rotary evaporator dan diuapkan hingga kering dan ditimbang ekstrak kering yang telah diperoleh.

\section{Identifikasi Metabolit Sekunder}

\section{Uji Alkaloid}

Ekstrak ditambahkan 5 mL HCL 2N. Kemudian larutan dibagi kedalam tiga tabung reansi. Tabung 1 ditambahkan larutan Dragendroff, tabung 2 ditambahkan larutan Mayer dan tabung 3 ditambahkan pereaksi Wagner. Reaksi positif bila terbentuk endapan jingga pada tabung 1 , reaksi positif bila terbentuk endapanputih pada tabung 2 dan reaksi positif terbentuk pada tabung 3 berwarna endapan coklat.

\section{Uji flavonoid}

Ekstrak ditambahkan dengan air panas, didihkan selama 5 menit kemudian disaring. Ditambahkan 0,05 mg serbuk Mg dan 1mL HCL pekat, kemudian dikocok kuat-kuat. Uji positif terbentuk warna merah, kuning atau jingga 


\section{Uji fenolik}

Ekstrak ditambahkan dengan 1Ml larutan Fe(III) klorida 10\% jika uji positif terbentuk warna biru tua, biru kehitaman atau hitam kehijauan menunjukan adanya senyawa fenolik

\section{Uji Steroid dan Tripernoid}

Ekstrak 1 gram ditambahkan asam asetat glasial sebanyak 10 tetes dan asam sulfat pekat sebanyak 2 tetes. Larutan dikocok perlahan dan dibiarkan selama beberapa menit. Jika positif steroid berwarna biru atau hijau sedangkan tripernoid berwarna merah atau ungu.

\section{Uji Saponin}

Ekstrak dimasukkan kedalam tabung reaksi lalu ditambahkan air panas lalu didinginkan lalu dikocok kuat selama 10 detik lalu ditambahkan 1 tetes HCL 2N. Uji positif jika berbentuk buih yang stabil 1-10 cm sekama kurang dari 10 menit.

\section{Pengujian Antibakteri}

Aktivitas antibakteri dilakukan pembuatan medium NA terlenih dahulu. Serbuk NA dilarutkan dengan aquadest lalu dipanaskan diatas hot plate. Setelah larut sempurna NA dilakukan proses sterilisasi dengan autoklaf pada suhu $121^{\circ} \mathrm{C}$ selama 15 menit. Selanjutnya dilakukan pembuatan biakan bakteri dengan menanamkan bakteri pada permukaan media NA yang telah dipadatkan dengan metode agar miring yang telah memadat didalam tabung reaksi dan diinkubasi seama $1 \times 24$ jam. Setelah inkubasi dilanjutkan pembuatan suspensi bakteri menggunakan $\mathrm{NaCl}$ 0,9\% hingga diperoleh 1:40.

Pengujian ekstrak daun jeruk sambal dilakukan pada medium NA dengan difusi agar. Sebanyak 0,02 mL suspensi bakteri 1:40 dalam $10 \mathrm{~mL}$ medium NA dimasukkan kedalam cawan petri steril kemudian dihomogenkan secara perlahan lalu dipadatkan medium NA tersebut. Rendam paper disc didalam masing-masing konsentrasi $(10 \%, 20 \%, 30 \%, 40 \%, 50 \%$ serta aquadeset sebagai kontrol negatif) selama 30 menit. Kemudian dimasukkan paper disc dipermukaan medium NA yang telah padat dan inkubasi selama $1 \times 24$ jam. 


\section{HASIL DAN PEMBAHASAN}

\section{Identifikasi Metabolit Sekunder}

Metabolit sekunder adalah senyawa metabolit yang tidak esensial bagi pertumbuhan organisme dan ditemukan dalam bentuk yang unik atau berbeda-beda antara spesies yang satu dan lainnya. Fungsi metabolit sekunder adalah untuk mempertahankan diri dari kondisi lingkungan yang kurang menguntungkan, misalnya untuk mengatasi hama dan penyakit (Rasyid, 2012).

Berdasarkan hasil identifikasi golongan metabolit sekunder terhadap ekstrak daun jeruk sambal diperoleh hasil golongan senyawa metabolit sekunder yaitu alkaloid, fenolik dan tanin.

Tabel 1. Hasil Identifikasi Golongan Metabolit Sekunder Daun Jeruk Sambal (Citrus Microcarpa)

\begin{tabular}{|c|c|c|c|c|c|c|c|}
\hline Sampel & & & Uji Me & bolit $\mathrm{Se}$ & under & & \\
\hline \multirow{2}{*}{$\begin{array}{c}\text { Ekstrak } \\
\text { Etanol }\end{array}$} & Alkaloid & Flavonoid & Fenolik & Tanin & Steroid & Tripernoid & Saponin \\
\hline & + & - & + & + & - & - & - \\
\hline
\end{tabular}

\section{Pengujian Aktivitas Antibakteri}

Pengujian aktivitas antibakteri daun jeruk sambal dilakulan dengan menggunakan 5 variasi konsentrasi yaitu 10\%, 20\%, 30\%, 40\%, 50\% dengan bakteri uji Staphylococcus aureus, Salmonella thypi, Bacillus subtilis dan Escherichia coli. Hasil uji antibakteri ekstrak daun jeruk sambal sebagai berikut. Gambar 1. 


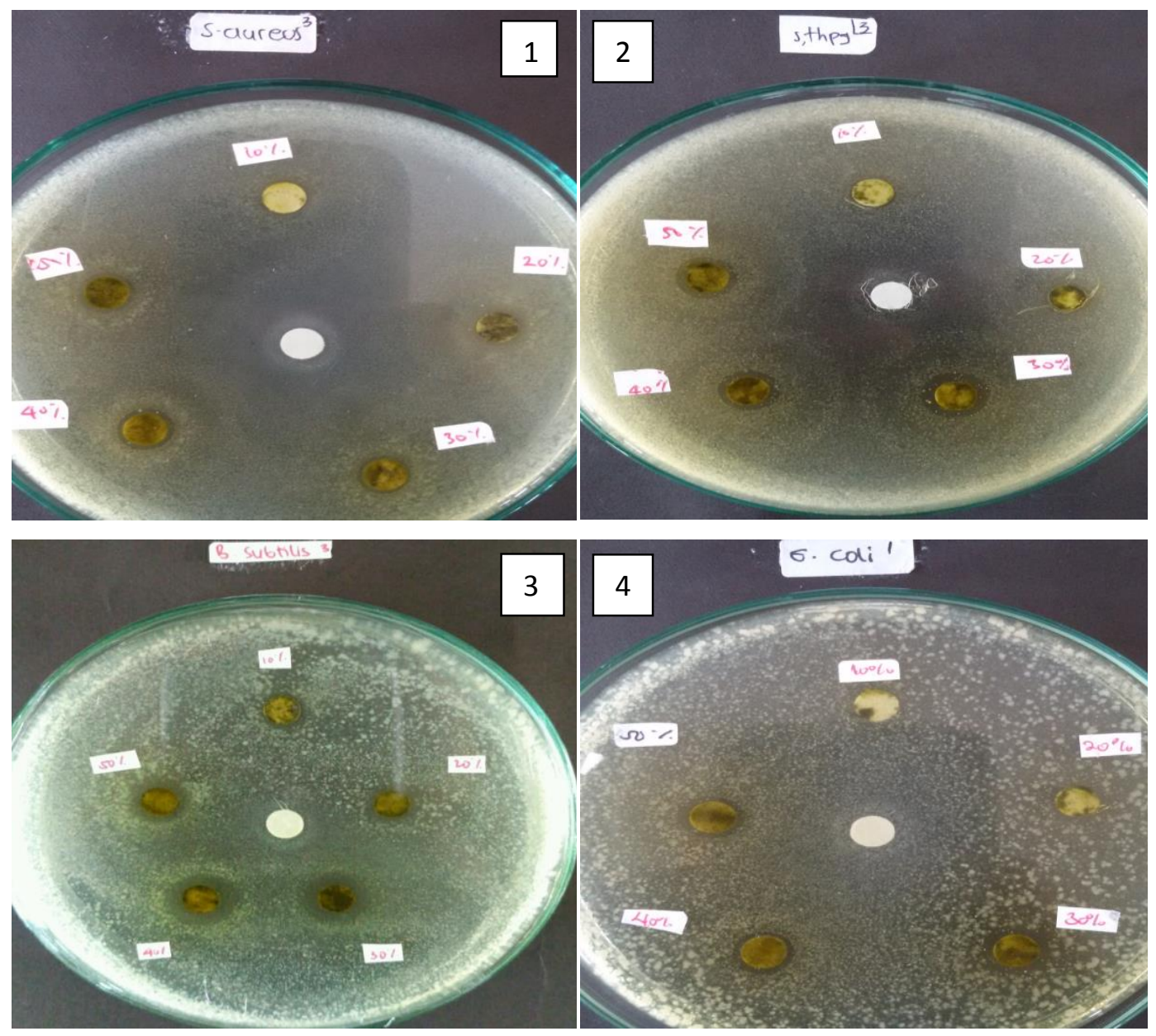

Gambar 1. Uji Aktivitas Antibakteri Daun Jeruk Sambal (Citrus Microcarpa) Terhadap Beberapa Bakteri Patogen Staphylococcus aureus (1), Salmonella thypi (2), Bacillus subtilis (3) dan Escherichia coli (4).

Berdasarkan hasil pengujian antibakteri ekstrak dengan bakteri Staphylococcus aureus, Salmonella thypi, Bacillus subtilis dan Escherichia coli menunjukan adanya ekstrak daun jeruk memiliki aktivitas sebagai antibakteri. Hal ini disimpulkan berdasarkan zona bening yang terdapat didaerah paper disc. Pada pengujian ini menggunakan 5 (lima) konsentrasi dan menggunakan kontrol negatif dengan menggunakan aquadest. Kontrol negatif pada setiap cawan perti tidak terdapat zona bening sehingga dapat diketahui bahwa pelarut dengan kontrol negatif tidak menimbulkan aktivtas sebagai antibakteri.

Hasil zona bening setiap konsentrasi dan setiap bakteri berbeda-beda seperti yang terdapat pada tabel 2. 
Tabel 2. Diameter Zona Bunuh Ekstrak Daun Jeruk Sambal (Citrus Microcarpa)

\begin{tabular}{cccccc}
\hline Sampel & Konsentr & \multicolumn{4}{c}{ Rerata Diameter Zona Bunuh (mm) } \\
\cline { 2 - 6 } & asi \% & S. aureus & S. thypi & B. subtilis & E. coli \\
\hline Ekstrak Etanol & $10 \%$ & - & - & - & - \\
\cline { 2 - 6 } $\begin{array}{c}\text { Daun Jeruk } \\
\text { Sambal (Citrus } \\
\text { Microcarpa) }\end{array}$ & $20 \%$ & 6,12 & 6,55 & 6,01 & 6,93 \\
\cline { 2 - 6 } & $30 \%$ & 7,22 & 7,83 & 7,02 & 7,22 \\
\cline { 2 - 6 } & $40 \%$ & 8,00 & 7,58 & 7,30 & 8,00 \\
\hline $\begin{array}{c}\text { Kontrol } \\
\text { Negatif } \\
\text { (Aquadest) }\end{array}$ & 0 & 8,11 & 7,57 & 7,19 & 7,59 \\
\hline
\end{tabular}

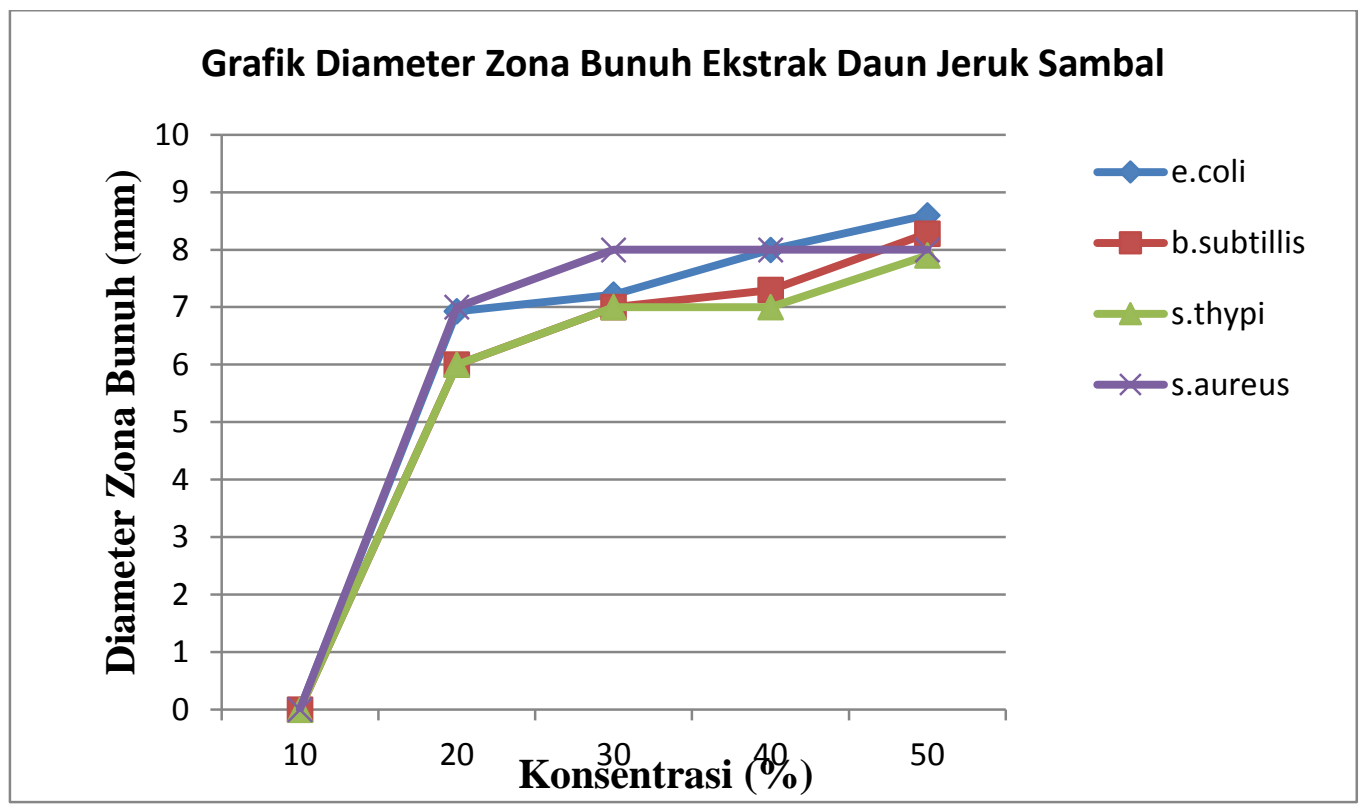

Gambar 2. Grafik Diameter Zona Bunuh Ekstrak Daun Jeruk Terhadap Bakteri Staphylococcus aureus, Salmonella thypi, Bacillus subtilis dan Escherichia coli.

Tabel 1 dan gambar 2 menunjukan aktivitas antibakteri ekstrak daun jeruk sambal dengan variasi konsentrasi terhadap bakteri. Pada hasil tersebut menujukkan semakin tinggi konsentrasi ekstrak daun jeruk sambal untuk diuji maka semakin besar juga aktivitas ekstrak sebagai antibakteri yang terlihat pada grafik diameter zona bunuh. Hal ini ditunjukkan dengan meningkatnya grafik diameter zona bunuh ekstrak daun jeruk sambal. Konsentrasi efektif ekstrak daun jeruk sambal merupakan konsentrasi yang memberikan aktivitas antibakteri paling besar dalam 
menghambat pertumbuhan bakteri yang diperlihatkan dengan adanya zona bunuh ataupun zona hambat.

Gambar 2 menunjukan bahwa konsentrasi efektif dalam membunuh atupun menghambat pertumbuhan bakteri adalah konsentrasi $50 \%$.

\section{Kesimpulan}

Berdasarkan penelitian yang telah dilakukan dapat diperoleh kesimpulan yaitu :

1. Ekstrak daun jeruk sambal (Citrus Microcarpa) memiliki aktivitas antibakteri terhadap bakteri Staphylococcus aureus, Salmonella thypi, Bacillus subtilis dan Escherichia coli.

2. Konsentrasi efektif ekstrak daun jeruk sambal untuk dapat memhambat pertumbuhan bakteri Staphylococcus aureus, Salmonella thypi, Bacillus subtilis dan Escherichia coli sebesar 50\%.

3. Ekstrak daun jeruk sambal mengandung senyawa metabolit sekunder berupa alkaloid, tanin dan fenolik.

\section{DAFTAR PUSTAKA}

Baud, Grace S, Meiske S. Sangai. Dan Harry S.J Koleangan. 2014. Analisis Senyawa Metabolit Sekunder Dan Uji Toksisitas Ekstrak Etanol Batang Tanaman Patah Tulang (Euphorbia tirucalli L.) Dengan Metode Brine Shrimp Lethality Test (BSLT). Jurnal Ilmiah Sains.Vol.14,no. 2

Jawetz E, Melnick GE, and Adelberg CA. 2008. Mikrobiologi kedokteran. Edisi I. Diterjemahkan oleh Penerjemah Bagian Mikrobiologi Fakultas Kedokteran Universitas Airlangga. Salemba Medika. Surabaya.

Rasyid, Abdullah. 2012. Identifikasi Senyawa Metabolit Sekunder Serta Uji Aktivitas Antibakteri dan Antioksidan Ekstrak Metanol Teripang Stichopus hermanii. Jurnal Ilmu dan Teknologi Kelautan Tropis. Vol. 4. No. 2: 360368.

Simaremare, Eva Susanty.2014. Skrining Fitofarmaka Ekstrak Etanol Daun Gatal (Laportea decumana (Roxb.)Wedd). Jurnal Pharmacy . vol 11, No.1

Wulandari,Mulyani.2013. Aktivitas Antioksidan Ekstran N-Heksan, Etil Asetat dan Metanol Kulit Buah Jeruk Sambal. Jurnal JJK.Vol 2 (2) hal 90-94. 